\begin{tabular}{|l|l|}
\hline & \\
&
\end{tabular}

\title{
O asseguramento dos direitos sociais a partir da política de Assistência Social para populações em situação de rua
}

\author{
Ensuring social rights based on the Social Assistance policy for homeless people
}

\author{
Tiago Martinelli ${ }^{1}$ \\ orcid.org/0000-0002-3496-0873 \\ timartinelli@yahoo.com.br

\section{Rodrigo dos Santos \\ Nunes ${ }^{2}$ \\ orcid.org/0000-0002-4523-8165 \\ rodrigo.s.nunes@hotmail.com}

\section{Veridiana Farias}

\section{Machado3}

orcid.org/0000-0003-1695-2113

veri.zea@gmail.com

Recebido em: 3/4/2020.

Aprovado em: 22/7/2020

Publicado em: 30 out. 2020.

\section{(c) (1)}

Artigo está licenciado sob forma de uma licença Creative Commons Atribuição 4.0 Internacional.
Resumo: Este texto tem por objetivo apresentar, na trajetória histórica brasileira, desde a Constituição Federal de 1988, os processos e o asseguramento dos direitos da população em situação de rua, sob a perspectiva da política pública de Assistência Social. A partir do arcabouço legal, aponta a restrição de acesso e a necessidade de estrutura para o atendimento das demandas dessa população. É na resistência e nas diferentes formas de manifestação desta população, que se tem a contribuição para o processo de garantia dos direitos sociais. No entanto, além de problematizar desafios, destaca também as conquistas junto à política de Assistência Social.

Palavras-chave: Assistência Social. População em Situação de Rua. Asseguramento.

Abstract: This text aims to present, in Brazilian historical trajectory, since the Federal Constitution of 1988, the processes and the assurance of the rights of the homeless population, from the perspective of the public policy of Social Assistance. Based on the legal framework, it points to a restriction of access and the need for a structure to meet the demands of this population. It is in the resistance and in the different forms of manifestation of this population that the contribution to the process of guaranteeing social rights is made. However, in addition to problematizing challenges, it also highlights the achievements with the Social Assistance policy. Keywords: Social Assistance. Homeless People. Ensure.

\section{Introdução}

Este texto tem por objetivo apresentar, desde a Constituição Federal de 1988, os processos e o asseguramento ${ }^{4}$ dos direitos da população em situação de rua, sob a perspectiva da política pública de Assistência Social. Em que pese o tema, a Constituição Federal do Brasil (1988) traz para o Estado democrático de direito a responsabilidade de atender a soberania, a cidadania, a dignidade da pessoa humana, os valores sociais do trabalho e da livre iniciativa e o pluralismo político.

Dessa forma, esses direitos fundamentais se estendem diretamente a todos/as os/as brasileiros/as. Além disso, o texto constitucional abriga objetivos que visam construir uma sociedade livre, justa e solidária, garantir o desenvolvimento nacional, erradicar a pobreza e a marginalização, reduzir as desigualdades sociais e regionais, e promover o bem de todos/as, sem preconceitos de origem, raça, sexo, cor, idade e sem quaisquer outras formas de discriminação (BRASIL, 1988).

\footnotetext{
Universidade Federal do Rio Grande do Sul (UFRGS), Porto Alegre, RS, Brasil

Pontifícia Universidade Católica do Rio Grande do Sul (PUCRS), Porto Alegre, RS, Brasil

Universidade do Vale do Rio dos Sinos (Unisinos), São Leopoldo, RS, Brasil

"Assegurar" remete a garantir. Remete, neste sentido, aos direitos sociais a serem garantidos em uma perspectiva de proteção social ampliada e materializada via políticas sociais públicas (PEREIRA, 2000).
} 
Ao realizar uma análise da realidade é possivel constatar algumas dificuldades em atingir esses objetivos. Não se vive em uma sociedade livre, justa e solidária se, nas suas condutas, está explícito para a população em situação de rua, o cerceamento da liberdade, de acesso à rua. Justa e solidária? Imperam o individualismo e a concentração de riqueza.

No que diz respeito à erradicação da pobreza e da marginalização, para essa população, esses objetivos passam à margem das condições mínimas de vida, uma vez que a maioria dos sujeitos está implicada pela segregação e exclusão. Associado a isso, está o grande desafio de reduzir as desigualdades sociais e regionais e de promover o bem de todos/as, sem preconceitos de origem, raça, sexo, cor, idade e sem quaisquer outras formas de discriminação.

O contraponto está, justamente, nas formas de resistência que esta população vem apresentando para ser reconhecida enquanto tal, e que contribuem para o processo de garantia de direitos naquilo que está previsto para todos/as, mas também no que se estabelece como peculiaridades de quem vive ou está na rua. No entanto, além de problematizar os desafios, cabe destacar também as conquistas junto à política de Assistência Social.

A partir da referida estrutura legal, pretende-se retratar o atendimento à população em situação de rua, naquilo que se consideram direitos sociais: saúde, educação, alimentação, previdência, assistência social, moradia, segurança, cultura, esporte, lazer, trabalho e renda. O fato é que, para esta população, há restrição de acesso a esses direitos, e isso faz com que a "dignidade humana" se objetive limitadamente por meio de benefícios, programas, serviços e projetos voltados ao atendimento das necessidades desse segmento. ${ }^{5}$

\section{Sistema Único de Assistência Social e a referência de proteção para a população em situação de rua}

Reconhecer, na Política Nacional de Assistência Social (BRASIL, 2004), o atendimento aos sujeitos que vivenciam a situação de rua no âmbito do Sistema Único de Assistência Social é mais uma conquista para uma política pública da seguridade social não contributiva e que vem se ampliando, alicerçada na sociedade em uma perspectiva de direito social. Nos indicadores territoriais, mapeamentos, diagnósticos e estudos acadêmicos sobre a situação de rua, percebem-se situações multicausais nos processos de "rualização". ${ }^{6}$ Todavia, é importante destacar que essa concepção não deve permitir a culpabilização de famílias e sujeitos (NUNES, 2019).

Entre outras diretrizes, para a Assistência Social, estão a primazia da responsabilidade do Estado, o controle social, com a participação popular, e a territorialização. Com isso, amplia-se a parcela da população que vem acessando a política ou mesmo gerando oportunidades àqueles sujeitos que antes enfrentavam maiores dificuldades para serem atendidos. ${ }^{7}$ A necessidade de acesso ${ }^{8}$ aos serviços, programas e benefícios é perceptivel "[...] nas parcelas da população onde há maiores índices de desemprego e de baixa renda dos adultos" (BRASIL, 2004, p. 19). Nesse sentido, marcada pelas proteções básica e especial, inclui-se ao grau de risco e de vulnerabilidade a população em situação de rua. ${ }^{9}$

No âmbito institucional, o que se apresenta historicamente são os abrigos e asilos, cuja fina-

\footnotetext{
5 Cabe destacar que a proposta deste texto não é retratar o conjunto de pesquisas, censos e outros estudos que foram realizados no Brasil. No entanto a contagem da população em situação de rua e dos censos realizados é de grande importância para compor os diferentes processos, desde a elaboração até a avaliação das politicas sociais.

6 "[...] Ver esta situação como estado e não como processo é um modo de reiterá-la, sem reconhecer a perspectiva do movimento de superação - e essa parece ser uma questão central. [...] Visto como determinação, uma situação social pouco apresenta em termos de perspectivas de superação" (PRATES; PRATES; MACHADO, 2011, p. 194).

7 "[...] ao agir nas capilaridades dos territórios e se confrontar com a dinâmica do real, no campo das informações, essa política inaugura uma outra perspectiva de análise ao tornar visiveis aqueles setores da sociedade brasileira tradicionalmente tidos como invisiveis ou excluidos das estatísticas - população em situação de rua, adolescentes em conflito com a lei, indígenas, quilombolas, idosos, pessoas com deficiência (BRASIL, 2004, p. 11).

8 "[...] existem familias com as mais diversas situações socioeconômicas que induzem à violação dos direitos de seus membros, em especial, de suas crianças, adolescentes, jovens, idosos e pessoas com deficiência, além da geração de outros fenômenos como, por exemplo, pessoas em situação de rua, migrantes, idosos abandonados que estão nesta condição não pela ausência de renda, mas por outras variáveis da exclusão social" (BRASIL, 2004, p. 30).

9 Vale destacar que a Política Nacional de Assistência Social, pautada pela equidade, considera grau diferenciado de atenção, além da população em situação de rua, indígenas, quilombolas, adolescentes em conflito com a lei (BRASIL, 2004).
} 
Lidade estava diretamente alinhada ao projeto de afastá-los do convívio social e familiar, na forma de "depósitos" de crianças e adolescentes (os chamados menores), pessoas com deficiências (física e/ ou mental, ou seja, os loucos) e idosos (os velhos). Muitas dessas instituições permanecem e, no que toca à Assistência Social, passam por um processo de reordenamento, em uma perspectiva de acesso à proteção social e efetivação da garantia de direitos. Esse processo, em constante adequação e transição, pode ser identificado pelo próprio uso das terminologias utilizadas para os serviços e para cada segmento populacional, como é o caso dos orfanatos (crianças e adolescentes), asilos (idosos) e hospícios (pessoas com deficiência).

Pessoas que fazem uso abusivo de álcool e de outras drogas, principalmente as que estão em situação de rua, atualmente estão colocadas no lugar dos mencionados "loucos", em retrocesso no tempo. Geralmente, para eles, a ideia de tratamento ou de cuidado ainda permanece fortemente pautada por espaços de "clausura", em um processo constituido por longas internações, em espaços afastados, como clínicas ou nas chamadas comunidades terapêuticas, as quais não são consideradas dispositivos regulados pelo SUS, nem pelo SUAS. ${ }^{10}$

No que tange a esse debate, a proteção social especial ${ }^{11}$, cujos serviços estão tipificados, "[...] deve priorizar a reestruturação dos serviços de abrigamento dos indivíduos que, por uma série de fatores, não contam mais com a proteção e o cuidado de suas familias, para as novas modalidades de atendimento" (BRASIL, 2004, p. 31). Naquilo que está previsto à população em situação de rua, devem ser priorizados os "[...] serviços que possibilitem a organização de um novo projeto de vida, visando criar condições para adquirirem referências na sociedade brasileira, enquanto sujeitos de direito" (BRASIL, 2004, p. 31).

A Política Nacional de Assistência Social subsidia a Lei n 11.258, de 2005 (BRASIL, 2006b), que, além de atualizar a Lei Orgânica de Assistência Social (BRASIL, 1993), inclui, no artigo 23, a prerrogativa de que, na organização dos serviços, deverão ser criados programas destinados a essas pessoas. ${ }^{12}$

Cabe destaque, assim como o resgate da legislação, tratado aqui como processos que demonstra avanços e desafios, o I Encontro Nacional sobre População em Situação de Rua, realizado em setembro de $2005^{13}$, em Brasília, cujo objetivo estava em "[...] discutir os desafios e estratégias para a construção das políticas públicas para a população em situação de rua" (BRASIL, 2006a, p. 7). Reafirmar os desafios apresentados naquele encontro é poder identificar aqueles que foram atingidos, aqueles que estão em processo e ainda os que precisam ser efetivados:

Produção de informações sobre a população em situação de rua; Superar a cultura social do preconceito, da desvalia, da intolerância e do assistencialismo em relação a esse público: Apoiar e respeitar o processo de organização, assegurando o protagonismo do segmento, e autonomia em relação ao Estado e às organizações não governamentais; Articular as politicas setoriais e adequá-las às demandas do segmento com base em principios universalizantes, éticos, e com respeito aos direitos humanos; Assegurar uma linha contínua de financiamento no âmbito dos governos Federal, estaduais e municipais, por meio da utilização de recursos orçamentários próprios, ou concessão de incentivos fiscais a pessoas físicas e jurídicas: Assegurar ações educativas de massa, considerando a necessidade de desenvolvimento de campanhas de mobilização e sensibilização para o entendimento da questão, dirigidas à sociedade como um todo; Mobilizar e adequar

\footnotetext{
10 Em 2019 foi lançada a chamada "nova" Política Nacional sobre Drogas. O texto é explícito em referir que quem irá articular e coordenar a implementação da referida política, no âmbito de suas competências, são a Secretaria Nacional de Cuidados e Prevenção às Drogas, do Ministério da Cidadania, e a Secretaria Nacional de Políticas sobre Drogas, do Ministério da Justiça e da Segurança Pública.

${ }_{11}$ "A proteção social especial é a modalidade de atendimento assistencial destinada a familias e individuos que se encontram em situação de risco pessoal e social, por ocorrência de abandono, maus-tratos físicos e/ou psíquicos, abuso sexual, uso de substâncias psicoativas, cumprimento de medidas socioeducativas, situação de rua, situação de trabalho infantil, entre outras" (BRASIL, 2004, p. 31). 12 "Artigo 23. Entendem-se por serviços socioassistenciais as atividades continuadas que visem à melhoria de vida da população e cujas ações, voltadas para as necessidades básicas, observem os objetivos, principios e diretrizes estabelecidos nesta Lei. § 10 O regulamento instituirá os serviços socioassistenciais. $§ 20$ Na organização dos serviços da assistência social serão criados programas de amparo, entre outros: I - às crianças e adolescentes em situação de risco pessoal e social, em cumprimento ao disposto no art. 227 da Constituição Federal e na Lei no 8.069, de 13 de julho de 1990 (Estatuto da Criança e do Adolescente); II - às pessoas que vivem em situação de rua." 13 Cabe lembrar que na trajetória de lutas da população em situação de rua existem marcos de resistência, como por exemplo, na cidade de São Paulo, o decreto n. 28.649/89, assinado pela prefeita Luiza Erundina de Souza, que reconheceu o trabalho dos catadores de pape das ruas. Em 1991 foi instituido o dia 10 de maio como Dia de Luta da População em Situação de Rua. Neste mesmo ano, a aliança entre a prefeitura de São Paulo e ONGs da cidade concluíram o primeiro levantamento da população em situação de rua na área central da cidade. São Paulo foi a primeira cidade a instituir os direitos da população em situação de rua em lei (Lei municipal 12.316/97) (SPOSATI, 2009).
} 
os serviços de segurança e justiça, de modo a prevenir e responsabilizar os culpados por crimes cometidos contra a população em situação de rua, revertendo a situação de impunidade; Capacitar e habilitar o quadro de pessoal das instituições que prestam atendimento a esse segmento (BRASIL, 2006a, p. 41).

Em 2006, foi instituido um Grupo de Trabalho Interministerial (GTI), coordenado pelo Ministério do Desenvolvimento Social e Combate à Fome (MDS), cuja finalidade estava, justamente, em elaborar estudos e apresentar propostas de políticas públicas para a inclusão social da população em situação de rua. ${ }^{14}$ Marco importante para a realização de estudos que devessem primar pela ação intersetorial entre as políticas públicas de assistência social, saúde, educação, habitação, trabalho e renda, cultura e garantia de direitos humanos.

Ainda no ano de 2006, criou-se a Portaria MDS $n^{\circ} 381$, de 12 de dezembro, que assegurou recursos do cofinanciamento federal para municípios com mais de 300.000 habitantes, com população em situação de rua, visando ao apoio à oferta de serviços de acolhimento destinados a esse público.

Em maio de 2009, aconteceu o II Encontro Nacional sobre População em Situação de Rua, também em Brasilia, e teve como objetivo debater a Politica Nacional para Inclusão da População em Situação de Rua e também a participação do Movimento Nacional da População de Rua em atividades do movimento social, desde a implementação da política (BRASIL, 2009b). É importante referir que o Movimento Nacional da População de Rua nasce na Região Sudeste, no ano de 2004, a partir do que ficou conhecido como o Massacre da Sé, em São Paulo. Nele, 15 pessoas foram agredidas por uma milícia policial enquanto dormiam, sendo que sete morreram. ${ }^{15}$ Esse episódio é um dos fatores que impulsionou a organização política das pessoas em situação de rua e sua rede de apoio (BOVE; FIGUEIREDO, 2015).

$O$ encontro aprovou os princípios ${ }^{16}$ de uma Politica Nacional para a População em Situação de Rua, como o respeito à dignidade do ser humano, o direito ao usufruto e à permanência na cidade e a garantia e a defesa de direitos fundamentais, combatendo práticas higienistas e ações preconceituosas e violentas. Aprovou também diretrizes tais como: a formulação e implementação de políticas públicas acessiveis de saúde, educação, habitação, lazer e cultura, respeitando a diversidade humana em suas diferentes expressões; o incentivo à organização política da população em situação de rua; e a criação de uma Secretaria Especial de Promoção da Política Nacional de Inclusão da População em Situação de Rua (BRASIL, 2009b).

Consideraram-se, assim, avanços junto à politica de Assistência Social no que se refere à população em Situação de Rua, com destaque também para a Resolução $n^{\circ} 109$, de 11 de novembro de 2009, do Conselho Nacional de Assistência Social, que trata da Tipificação Nacional de Serviços Socioassistenciais. A tipificação está organizada por niveis de complexidade do SUAS, em Proteção Social Básica e Proteção Social Especial de Média e Alta Complexidade. Destacam-se, nesse documento, os serviços socioassistenciais em âmbito nacional. Dentre eles, estão os destinados ao atendimento da População em Situação de Rua na Proteção Social Especial (PSE): Serviço Especializado em Abordagem Social; Serviço Especializado para Pessoas em Situação de Rua; Serviço de Acolhimento Institucional (que incluem adultos e famílias em situação de rua); e Serviço de Acolhimento em República (que inclui adultos em processo de saída das ruas).

\footnotetext{
14 A cidade de Porto Alegre teve seu primeiro censo em 1994/95 pela Faculdade de Serviço Social da PUCRS (PRATES; PRATES; MACHADO, 2011), em parceria com a prefeitura, que contabilizou 222 sujeitos adultos em situação de rua. Em 2007, a UFRGS, também em parceria com a prefeitura, contou 1.203. O último censo realizado em Porto Alegre cadastrou 2.115 adultos de ambos os sexos identificados como em "situação de rua" (UFRGS; FASC; PMPA, 2016). Em 1998 já havia sido realizada a primeira contagem em Belo Horizonte Outra cidade brasileira a ter feito uma pesquisa com este segmento populacional foi Recife, que registrou 1.164 pessoas em 2005.

15 "Segundo as investigações, os crimes ocorreram para silenciar os moradores de rua que sabiam do envolvimento de policiais nos esquemas de tráfico de drogas da região. Na época, um segurança particular e seis policiais militares foram denunciados. Três soldados foram presos, mas soltos no mesmo ano por falta de provas" (ALBUQUERQUE, 2015).

16 São principios da Política Nacional para a População em Situação de Rua, além da igualdade e equidade: I - respeito à dignidade da pessoa humana; II - direito à convivência familiar e comunitária; III - valorização e respeito à vida e à cidadania; IV -atendimento humanizado e universalizado; e $V$ - respeito às condições sociais e diferenças de origem, raça, idade, nacionalidade, gênero, orientação sexual e religiosa, com atenção especial às pessoas com deficiência (BRASIL, 2009a).
} 
Os processos de regulamentação e de instâncias de participação e mobilização tiveram como referência o SUAS, para os planejamentos de estratégias de enfrentamento das situações de vulnerabilidade que têm na pobreza seu núcleo central. Ainda em dezembro de 2009, por meio do Decreto $n^{\circ}$ 7.053, instituíram-se a Política Nacional para a População em Situação de Rua e o seu Comitê Intersetorial de Acompanhamento e Monitoramento (BRASIL, 2009a).

Nessa política é que se tem uma definição sobre população em situação de rua:

[...] considera-se população em situação de rua o grupo populacional heterogêneo que possui em comum a pobreza extrema, os vinculos familiares interrompidos ou fragilizados e a inexistência de moradia convencional regular, e que utiliza os logradouros públicos e as áreas degradadas como espaço de moradia e de sustento, de forma temporária ou permanente. bem como as unidades de acolhimento para pernoite temporário ou como moradia provisória (BRASIL, 2009a, s. p.).

Através dos estudos realizados com os sujeitos que vivenciam a situação de rua, essa política problematiza o fenômeno rualização como uma expressão da questão social ${ }^{17}$ (NUNES, 2010). A rualização ${ }^{18}$ se constitui como um "processo que se conforma a partir de múltiplos condicionantes".

Pode iniciar na esfera doméstica, esfera das relações primárias, e resulta na rua como espaço de sobrevivência e/ou moradia. Em algumas situações ida para a rua pode se constituir em alternativa de resistência a abusos, exploração e outras formas de violação de direitos que ocorrem em casa ou no território (NUNES, 2019, p. 122).

A fim de fazer o enfrentamento à situação de rua, os municipios e estados que aderirem à Política Nacional para a População em Situação de Rua (2009a) deverão instituir comitês gestores intersetoriais, integrados por representantes das áreas relacionadas ao atendimento da população em situação de rua, com a participação de fóruns, movimentos e entidades representativas desse segmento da po- pulação. São esses espaços que visam materializar as ações previstas na Política Nacional.

Respondendo a um dos objetivos do plano de enfrentamento e ao encontro dos encaminhamentos do Encontro Nacional da População em Situação de Rua, a Política de Inclusão (que se coaduna com a de Assistência Social, dentre outras) define que

[...] o Poder Executivo Federal poderá firmar convênios com entidades públicas e privadas, sem fins lucrativos, para o desenvolvimento e a execução de projetos que beneficiem a população em situação de rua e estejam de acordo com os principios, diretrizes e objetivos que orientam a Política Nacional de Inclusão para a População em Situação de Rua (BRASIL, 2009a, s. p.).

Passivel de críticas, essa política, ainda sem aderência de grande parte dos municípios brasileiros, tem a intenção de ser um instrumento que assegure minimamente esforços na garantia de suas diretrizes:

[...] promoção dos direitos civis, políticos, econômicos, sociais, culturais e ambientais; responsabilidade do poder público pela sua elaboração e financiamento; articulação das políticas públicas federais, estaduais, municipais e do Distrito Federal; integração das políticas públicas em cada nível de governo; integração dos esforços do poder público e da sociedade civil para sua execução; participação da sociedade civil por meio de entidades, fóruns e organizações da população em situação de rua [...] (BRASIL, 2009a, s. p.).

Essa política refere a necessidade da intersetorialidade entre as políticas públicas ${ }^{19}$, expressa em seus objetivos, que almejam assegurar o acesso amplo, simplificado e seguro aos serviços e programas que integram as diferentes politicas públicas.

[...] na elaboração, acompanhamento e monitoramento das políticas públicas; incentivo e apoio à organização da população em situação de rua e à sua participação nas diversas instâncias de formulação, controle social, monitoramento e avaliação das políticas públicas; respeito às singularidades de cada território e ao aproveitamento das potencialidades

\footnotetext{
17 "A questão social é apreendida como expressão das desigualdades sociais: o anverso do desenvolvimento das forças produtivas do trabalho social. Sua produção/reprodução assume perfis e expressões historicamente particulares na cena contemporânea" (IAMAMOTO, 2004, p. 10-11).

18 Vale conferir, sobre o tema, especialmente, Prates et al. (2011) e Nunes (2019).

19 Sobre a intersetorialidade: "tem sido um dos debates importantes tanto na academia quanto no trabalho de profissionais que são desafiados constantemente nos seus espaços a intervir qualificadamente e de forma a garantir direitos sociais a população" (NUNES: SILVA; ALMEIDA, 2016, p. 15).
} 
e recursos locais e regionais na elaboração, desenvolvimento, acompanhamento e monitoramento das políticas públicas; implantação e ampliação das ações educativas destinadas à superação do preconceito, e de capacitação dos servidores públicos para melhoria da qualidade e respeito no atendimento deste grupo populacional; e democratização do acesso e fruição dos espaços e serviços públicos (BRASIL, 2009a, s. p.).

Apesar de suas limitações, tem-se um documento que cumpre com preceitos legais e, assim, objetiva "[...] garantir a formação e capacitação permanente de profissionais e gestores para atuação no desenvolvimento de políticas públicas intersetoriais, transversais e intergovernamentais direcionadas às pessoas em situação de rua" (BRASIL, 2009a).

Em um processo de planejamento e monitoramento das políticas sociais, fica instituida a Instrução Operacional nº 07, de 22 de novembro de 2010, conjunta à Secretaria Nacional de Assistência Social (SNAS) e à Secretaria Nacional de Renda e Cidadania (Senarc), que reúne orientações aos municipios e Distrito Federal para a inclusão de pessoas em situação de rua no Cadastro Único para Programas Sociais do Governo Federal (Cadúnico). A defesa que se faz é que, assim como os/as demais usuários/as, as pessoas em situação de rua devem ser incluidas no Cadastro Único, principalmente para

[...] potencializar o acesso dessa população aos programas usuários do Cadastro Único e à rede de serviços socioassistenciais, bem como a produção de informações que contribuam para o aprimoramento da atenção a esse segmento nas diversas políticas públicas (BRASIL, 2010, s. p.).

Para quem vive na rua, em decorrência daquilo que sempre foi e ainda pode ser uma dificuldade para se referenciar territorialmente - ter um endereço -, poderá ser utilizado o endereço da unidade de serviço da rede socioassistencial que a pessoa tenha como referência ou, na ausência deste, o endereço da instituição de acolhimento indicada pelo entrevistado (Portaria GM n 177, de 16 de junho de 2011).
Cabe resgatar a Resolução $n^{\circ}$ 7, de 07 de junho de 2010, da Comissão Intergestores Tripartite (CIT), que pactua critérios de partilha de recursos do cofinanciamento federal para a Expansão dos Serviços Socioassistenciais, de 2010, com recursos advindos do Plano Integrado de Enfrentamento ao Uso de Crack e de Outras Drogas (Decreto $n^{\circ}$ 7.179, de 20 de maio de 2010). Nessa mesma lógica de financiamento, a Portaria $n^{\circ}$ 843, de 28 de dezembro de 2010, dispõe sobre o cofinanciamento federal, por meio do Piso Fixo de Média Complexidade, dos serviços socioassistenciais ofertados pelos Centros de Referência Especializados de Assistência Social (Creas) e pelos Centros de Referência Especializados para População em Situação de Rua. Essa portaria foi alterada pela Portaria n 139 , de 28 de junho de 2012, dispondo sobre o cofinanciamento federal dos serviços ofertados pelos Creas e Centros Pop.

Desde 2009, houve a necessidade de instituição do Comitê Intersetorial de Acompanhamento e Monitoramento da Política Nacional para a População em Situação de Rua, integrado por representantes da sociedade civil e pelo governo. Ilustrativo disso, pode-se trazer a situação de Porto Alegre ${ }^{20}$, município no qual, em 2011, e mais recentemente, por meio do Decreto $n^{\circ}$ 19.087, de 22 de julho de $2015^{21}$, retoma-se a necessidade de se instituir o Comitê Intersetorial da Política Municipal para a População em Situação de Rua (Comitê POPRUA) e revoga-se o Decreto $n^{\circ}$ 17.111, de 20 de junho de 2011. Um Comitê em que os gestores indiquem a representação do movimento social, como foi o caso daquele constituido em 2011 em Porto Alegre, ou em que não exista a participação organizada desse público, provavelmente, terá pouca legitimidade ou não cumprirá com o principal objetivo: o protagonismo das pessoas em situação de rua como base.

Inconteste, também, a necessidade de alternativas emancipatórias no sentido de estimular a participação e o protagonismo dos sujeitos, bem como a problematização destes estudos e indicadores

\footnotetext{
20 Justifica-se a referência da cidade de Porto Alegre, como ilustrativa em diferentes partes deste artigo, por ser espaço de estudo e de trabalho dos/a autores.

${ }_{21}$ Em janeiro de 2016, foi aprovado o Regimento Interno do Comitê Intersetorial de Acompanhamento e Monitoramento da Política Municipal para a População em Situação de Rua - Comitê POPRUA, através do Decreto n 19.282/2016 (PORTO ALEGRE, 2016).
} 
que desvendam vulnerabilidades e riscos sociais, a fim de subsidiar o planejamento, o monitoramento e a avaliação das políticas públicas. Nesse sentido é importante ressaltar que uma das principais estratégias que os comitês trazem em relação a sua constituição é a importância do protagonismo e da independência dos representantes do movimento social em relação aos indicados pelos governos. Nesses espaços de controle social, de monitoramento, de tensionamento e de possiveis construções em conjunto, faz-se essencial que os papéis estejam muito bem definidos.

Em relação à mudança de governos, deve-se considerar que é o movimento social das pessoas em situação de rua do Rio Grande do Sul, o MNPR, participante ativo no Comitê, que pressiona, através do Ministério Público, a retomada e a adequação do Comitê municipal. Ele é coordenado pela Secretaria de Direitos Humanos, justamente com o propósito de descentralizar a condução pela política de Assistência Social e reafirmar a importância de outras políticas se fazerem presentes quando o assunto se trata da rualização.

Os saberes das pessoas que vivenciam esses processos precisam ser considerados como base para que se construam políticas públicas e ações a partir das suas experiências. Os serviços de acolhimento a população e os trabalhadores implicados na política de assistência social, nesse caso, também têm papel de facilitadores para que a participação das pessoas atendidas seja estimulada, tanto dentro dos próprios serviços para pensar a política quanto para que possam se inserir nas organizações políticas de fóruns e de movimentos sociais voltados para o segmento populacional em situação de rua.

Há muito que se avançar, e a busca de tensionamento junto aos governos deve ser função dos movimentos sociais, com vistas à construção das adequações dos comitês e do funcionamento dos serviços, com apoio dos trabalhadores das políticas públicas e da sociedade civil.

\section{Conclusão}

A partir de 2009, muito se tinha avançado nos objetivos da Política Nacional para a População em
Situação de Rua, como o próprio acesso, ainda que dificultado por processos técnicos e burocráticos, aos benefícios previdenciários e assistenciais e aos programas de transferência de renda.

Incontestes, portanto, são as dificuldades em se criarem meios de articulação entre o Sistema Único de Assistência Social, o Sistema Único de Saúde e as demais politicas públicas para qualificar a oferta de serviços. Espaços e ações de segurança alimentar e nutricional são inexistentes ou insuficientes para proporcionar seu acesso permanente e com qualidade, pela população em situação de rua.

Ainda temos muito para avançar também em áreas da justiça, assim como a da segurança pública em relação a essa parcela da população. A questão da violência à qual elas são acometidas, muitas vezes, por agentes do próprio Estado, ainda está bastante invisibilizada

Na Assistência Social, percebem-se avanços como a instituição e a implementação dos Centros de Referência Especializados, que vêm qualificando o atendimento da população em situação de rua, no âmbito da Proteção Social Especial do Sistema Único de Assistência Social. Essa centralidade não exime aquilo que está previsto na Política Nacional para a População em Situação de Rua. Esse segmento populacional deverá ter assegurado o acesso amplo, simplificado e seguro aos serviços e programas que integram as demais politicas públicas.

Contudo, cabe ressaltar a importância dos estudos e pesquisas que se propõem a dar materialidade aos objetivos da Política Nacional para a População em Situação de Rua (2009), como, por exemplo, a contagem oficial da sua população, produção, sistematização e disseminação de dados e indicadores sociais, econômicos e culturais sobre a rede existente de cobertura de serviços públicos à ela. Além disso, devem estabelecer processos de ações educativas que contribuam para a formação da cultura de respeito, ética e solidariedade entre a população em situação de rua e os demais grupos sociais, de modo a resguardar a observância aos direitos humanos.

Não existem estatísticas oficiais sobre mortes e violências, nem um campo de registros que indique 
a condição de rualização nos instrumentos e no Sistema Integrado da Segurança Pública para possibilitar estratégias de identificação dos números e dos principais motivos destas violências. ${ }^{22}$ Nos espaços de encontro dos comitês, é possivel que os agentes possam construir essas estratégias.

Não se pode deixar de sinalizar como enormes dificuldades os recentes cortes orçamentários e as atuais prioridades dos gestores públicos, nos quais serviços estão deixando de funcionar, inclusive com sérias ameaças às politicas de seguridade social.

Diante disso, ao finalizar este texto, convocam-se todos e todas para assumirmos o compromisso na busca pelo asseguramento dos direitos da população (principalmente por meio de políticas sociais públicas), que se efetivarão e se fortalecerão quando construidas coletivamente junto aos movimentos da população em situação de rua buscando atender as demandas apontadas por eles.

\section{Referências}

ALBUQUERQUE, Flávia. Ato em São Paulo lembra 11 anos do massacre de moradores de rua na Praça da Sé. Agência Brasil, São Paulo, 19 ago. 2015.Disponivel em:http://agenciabrasil.ebc.com.br/geral/ noticia/2015-08/ato-em-sao-paulo-lembra-11-anos-da-massacre-de-moradores-de-rua-na-praca-da-se. Acesso em: 17 fev. 2020

BOVE, Cristina; FIGUEIREDO, Gladston. Secretaria de Direitos Humanos da Presidência da República - SDH/ $\mathrm{PR}$ e Faculdade Latino-Americana de Ciências Sociais Flacso Brasil. População de rua. Brasília, 2015. (Coleção Caravana de Educação em Direitos Humanos).

BRASIL. Ministério do Desenvolvimento Social e Combate à Fome. Secretaria Nacional de Assistência Social. Politica Nacional de Assistência Social (PNAS). Brasilia/ DF: MDS/SNAS/PNAS, nov. 2004.

BRASIL. Ministério do Desenvolvimento Social e Combate à Fome. Secretaria de Avaliação e Gestão da Informação. Secretaria Nacional de Assistência Social. I ENCONTRO NACIONAL SOBRE POPULACCÃO EM SITUAÇÃO DE RUA. Brasilia/DF: MDS, SAGI, SNAS, 2006a.
BRASIL. Presidência da República. Lei 11.258, de 30 de dezembro de 2005. Altera a Lei 8.742, de 7 de dezembro de 1993, que dispõe sobre a organização da Assistência Social para acrescentar o serviço de atendimento às pessoas que vivem em situação de rua. Diário Oficial da União, Brasilia, n. 1, seção p 1, p. 1, 2 jan. 2006b.

BRASIL. Presidência da República. Decreto nº 7053, de 23 de dezembro de 2009. Política Nacional para População em Situação de Rua. Brasilia, dez. $2009 a$.

BRASIL. Ministério do Desenvolvimento Social e Combate à Fome - MDS. Secretaria Nacional de Assistência Social. Secretaria de Avaliação e Gestão da Informação. Relatório do II Encontro Nacional sobre População em Situação de Rua. Brasília, 200gb.

BRASIL. Ministério do Desenvolvimento Social e Combate à Fome. Secretaria Nacional de Assistência Social. Norma Operacional Básica (NOB/SUAS). Sistema Único de Assistência Social (SUAS). Brasilia/DF: MDS/SNAS, dez. 2012.

IAMAMOTO, M. V. O serviço social no capitalismo. Temporalis, Brasilia, ABEPSS, a. II, n. 3, p. 09-32, 2004.

MACHADO, Veridiana Farias. Hoje, perdemos mais um grande companheiro de luta. Porto Alegre, 28 ago., 2020. Facebook: veridiana.fariasmachado. Disponivel em: https://www.facebook.com/veridiana.fariasmachado. Acesso em: 16 set. 2020.

NUNES, Rodrigo dos Santos. Processo de rualização como expressão da questão social em Gravatai: a interface da Política de Assistência Social no Herbert de Souza. Trabalho de Conclusão de Curso (Serviço Social) - Ulbra, Gravataí, 2010.

NUNES, Rodrigo dos Santos. Como a população em situação de rua está contemplada no processo de vigilância socioassistencial? Tese (Doutorado) - Programa de Pós-Graduação em Serviço Social, PUCRS, Porto Alegre, 2019.

NUNES, Rodrigo dos Santos; SILVA, Priscila Klein da; ALMEIDA, Vanessa Benedet de. Intersetorialidade: uma estratégia a partir do processo de consultoria e assessoria? In: III SERPINF E I SENPINF. Anais [...]. Porto Alegre: Edipucrs, 2016. Disponivel em: http://ebooks. pucrs.br/edipucrs/anais/serpinf/2016/assets/25.pdf. Acesso em: 17 fev. 2020.

PEREIRA, Potyara Amazoneida Pereira. Necessidades humanas: subsidios à critica dos mínimos sociais. São Paulo: Cortez, 2000.

PORTO ALEGRE. Decreto $n^{\circ}$ 19.282, de 7 de janeiro de 2016. Aprova o Regimento Interno do Comitê Intersetorial de Acompanhamento e Monitoramento da Política Municipal para a População em Situação de Rua - Comitê POPRUA. Porto Alegre, 2016.

\footnotetext{
22 "[No dia 28 de agosto de 2020], perdemos mais um grande companheiro de luta: Leandro Corrêa (Pedrinha). Faleceu de descaso, de negligência, de falta de moradia, de falta de acesso às diversas políticas públicas e aos diversos direitos que deveria ter. Leandro era jornalista do Boca de Rua, militante do MNPR do RS, foi integrante da luta por moradia da Ocupação Aldeia Pop Rua Zumbi dos Palmares e atualmente trabalhava no projeto de padaria Amada Massa. Leandro vai fazer muita falta, vai deixar muitas saudades a essa família outra que lhe acolheu. Vai em paz Pedrinha! Manda notícias nossas para a companheira Rita, para o Paulinho, para o Pelezinho, para a mãe Meque e para tantxs outrxs que por aqui passaram. Esses que tem um tempo menor de vida por falta de oportunidades, pela desigualdade que teima em nos expropriar as vidas, o direito de existir com plenitude. Mas, diga a todxs quando lá chegares que aqui não desistiremos de lutar, até que todxs possam existir com dignidade, com condições melhores de vida. Lutaremos sempre contra a necropolitica! Vá em paz irmão! Leandro Corrêa (Pedrinha): presente! 03/12/1983 + 28/08/2020" (MACHADO, 2020).
} 
PRATES, Jane Cruz; PRATES, Flavio Cruz; MACHADO, Simone. Populações em situação de rua: os processos de exclusão e inclusão precária vivenciados por esse segmento. Temporalis, Brasilia (DF), ano 11, n. 22, p. 191-215, jul./dez. 2011. https://doi.org/10.22422/ 2238-1856.2011V11n22p191-216

SPOSATI, Aldaiza. O caminho do reconhecimento dos direitos da população em situação de rua: de indivíduo a população. In: BRASIL. Ministério do Desenvolvimento Social e Combate à Fome. Rua: aprendendo a contar Pesquisa Nacional sobre a População em Situação de Rua. Brasilia/DF: MDS, Secretaria de Avaliação e Gestão da Informação; Secretaria Nacional de Assistência Social, 2009.

UFRGS; FASC; PMPA. Cadastro e mundo da população adulta em situação de rua de Porto Alegre/RS. Relatório Final. Porto Alegre: IFCH/UFRGS, 2016.

\section{Tiago Martinelli}

Professor no curso de Serviço Social da Universidade Federal do Rio Grande do Sul (UFRGS). Assistente social pela Universidade do Vale do Rio dos Sinos (Unisinos). Doutor e mestre em Serviço Social pela Pontificia Universidade Católica do Rio Grande do Sul (PUCRS). Integrante do Núcleo Terra, Trabalho e Politica Social (Departamento de Serviço Social/UFRGS) e do Núcleo de Estudos em Politicas e Economia Social (Nepes/PUCRS).

\section{Rodrigo dos Santos Nunes}

Pós-doutorando na Escola de Humanidades da PUCRS, vinculado ao Programa de Pós-graduação em Serviço Social. Doutor e mestre em Serviço Social pela PUCRS. Integrante do Núcleo de Estudos em Políticas e Economia Social (Nepes/PUCRS).

\section{Veridiana Farias Machado}

Educadora Social na Fundação de Assistência Social e Cidadania (Fasc). Graduada em Ciências Biológicas pela Universidade Luterana do Brasil (Ulbra). Graduanda em Psicologia pela Universidade do Vale do Rio dos Sinos (Unisinos).

Os autores são, também, apoiadores do Movimento Nacional da População em Situação de Rua - MNPR/RS.

\section{Endereço para correspondência}

\section{Tiago Martinelli}

Universidade Federal do Rio Grande do Sul

Instituto de Psicologia

Departamento de Serviço Social

Rua Ramiro Barcelos, 2600 - Bairro Santa Cecilia

Porto Alegre/RS

CEP: 90035-003 